\title{
PENINGKATAN KECERAHAN PADA PROSES SINTESIS SURFAKTAN NONIONIK ALKIL POLIGLIKOSIDA (APG) BERBASIS TAPIOKA DAN DODEKANOL
}

\author{
Februadi Bastian $^{1 *}$, Ani Suryani ${ }^{2)}$, dan Titi Candra Sunarti ${ }^{2)}$ \\ ${ }^{1)}$ Jurusan Teknologi Pertanian Fakultas Pertanian Universitas Hasanuddin \\ Jl. Perintis Kemerdekaan Km.10 Makassar 90245; Tlp. (0411) 431081 \\ ${ }^{2)}$ Departemen Teknologi Industri Pertanian Fakultas Teknologi Pertanian Institut Pertanian Bogor \\ Jl. Lingkar Akademik, Kampus IPB Darmaga, Bogor 16680; Telp. (0251) 8621974 \\ ${ }^{*}$ Penulis korenspondensi: februadi@gmail.com
}

\begin{abstract}
INCREASED CLARITY ON SYNTHESIS PROCESS OF ALKYL POLYGLYCOSIDES (APG) NON IONIC SURFACTANT BASED ON TAPIOKA AND DODECANOL. Alkyl polyglycosides $(A P G)$ is a nonionic surfactant that has been getting some green labels such as Ecocert, EU Eco-flower and Green Seal as an environmentally friendly surfactant. Sugar is the main raw material which is supplied the hydrophilic group, and fatty alcohol as hydrophobic group. Some undesirable compounds formed during the APG production and caused low quality. The aim of this research to increase the quality and performance of $A P G$, by controlling its process. Addition 0-10\% of activated carbon and 0-0.3\% of NaBH4 in APG pre-purification process; $2 \%(w / w)$ of $\mathrm{H}_{2} \mathrm{O}_{2}, 35 \%$ and $500 \mathrm{ppm}$ of $\mathrm{MgO}$ in the bleaching process were examined to process high quality and high performance of APG. The best APG was obtained from purification step by addition $0 \%$ of activated carbon and $0.2 \%$ of $\mathrm{NaBH} 4$, with the characteristics of clarity of 59.02(\%T); the ability to reduce surface and interfacial tensions at $1 \%$ concentration were $61.94 \%$ and $95.6 \%$ respectively; $81.71 \%$ of stability of emulsion, $62.5 \%$ of foam height and stable up to 315 minutes.
\end{abstract}

Keywords: alkyl polyglycoside; bleaching; nonionic surfactants; purification

\begin{abstract}
Abstrak
Alkil Poliglikosida (APG) merupakan surfaktan nonionic yang telah mendapatkan beberapa green label seperti Ecocert, EU Eco-flower Green Seal dan sebagainya sebagai surfaktan yang ramah lingkungan. Bahan dasar APG yaitu gula untuk membentuk gugus hidrofiliknya dan fatty alcohol untuk membentuk gugus hidrofobiknya. Permasalahan dalam produksi APG adalah timbulnya warna gelap yang tidak dikehendaki yang menyebabkan penurunan mutu APG. Tujuan dari penelitian ini yaitu untuk meningkatkan mutu dan kinerja dari APG. Untuk meningkatkan kecerahan APG, maka sebelum dilakukan proses destilasi dilakukan penambahan arang aktif 0-10\% serta $\mathrm{NaBH}_{4}$ 0-0,3\%. Pada proses pemucatan ditambahkan $2 \%$ (b/b) $\mathrm{H}_{2} \mathrm{O}_{2} 35 \%$ dan $\mathrm{MgO} 500$ ppm. Hasil terbaik yaitu penambahan arang aktif $0 \%$ dan $\mathrm{NaBH}_{4}$ 0,2\% dengan karakteristik kecerahan 59,02(\%T); kemampuan menurunkan tegangan permukaan dan antar muka pada konsentrasi $1 \%$ sebesar $61,94 \%$ dan 95,6\%; kestabilan emulsi 81,71\%, tinggi busa 62,5\% dan umur busa 315 menit.
\end{abstract}

Kata kunci: alkil poliglikosida, pemucatan, surfaktan nonionik, pemurnian

\section{PENDAHULUAN}

Surfaktan merupakan senyawa yang memiliki kemampuan menurunkan tegangan permukaan yang memiliki gugus hidrofilik dan hidrofobik dalam satu molekul. Gugus hidrofilik dan hidrofobik yang terdapat pada surfaktan menyebabkan surfaktan dapat digunakan sebagai bahan pembusa atau emulsifier dalam industri farmasi, kosmetik, kimia, pertanian dan pangan. Surfaktan sebagian besar diproduksi dari minyak bumi, namun ancaman akan kekurangan sumber energi tak terbarukan, menyebabkan industri yang memproduksi surfaktan beralih menggunakan bahan baku yang dapat diperbaharui (renewable) dan ramah lingkungan (Sukkary dkk., 2007).

Alkil poliglikosida (APG) merupakan surfaktan nonionik yang ramah lingkungan karena 
disintesis dengan menggunakan bahan baku yang berbasis karbohidrat dan alkohol lemak. APG telah mendapatkan beberapa green label seperti Ecocert, EU Eco-flower, Green Seal dan sebagainya sebagai surfaktan yang ramah lingkungan. APG juga tidak beracun atau berbahaya bagi manusia, memiliki sifat iritasi yang rendah pada kulit jika dibandingkan dengan surfaktan lainnya (Mehling dkk., 2007). Saat ini produksi APG dunia mencapai 85.000 ton/tahun (Hill, 2009). Permasalahan utama dalam sintesis surfaktan alkil poliglikosida yaitu terbentuknya warna gelap yang tidak diinginkan. Warna gelap diakibatkan oleh proses pencoklatan non enzimatis karena kandungan furfuraldehid pada pati. Penggunaan bahan baku yang berasal dari pati maupun gula-gula sederhana dalam pembuatan alkil poliglikosida sangat mudah terdegradasi akibat penggunaan suhu tinggi dan keadaan asam maupun basa selama proses sintesis. Proses degradasi inilah yang menghasilkan by-product yang tidak diinginkan karena menghasilkan warna gelap. Perbedaan kepolaran dari bahan baku sakarida dan alkohol lemak menyebabkan ikatan antara glukosa hasil degradasi pati dengan alkohol lemak sulit berikatan, sehingga glukosa membentuk sebuah polimer (polydextrose) yang berwarna kuning hingga coklat tua akibat kondisi asam, panas dan kandungan air yang yang cukup tinggi selama proses reaksi (Eskuchen dan Nitsche, 1997).

Menurut Wuest dkk. (1992), proses pembuatan APG menggunakan pati kentang sebagai sumber hidrofiliknya dilakukan dengan beberapa tahapan proses. Pertama yaitu tahapan butanolisis dengan menggunakan suhu $145^{\circ} \mathrm{C}$ dengan tekanan 5-7 bar selama 30 menit dengan menggunakan katalis asam.

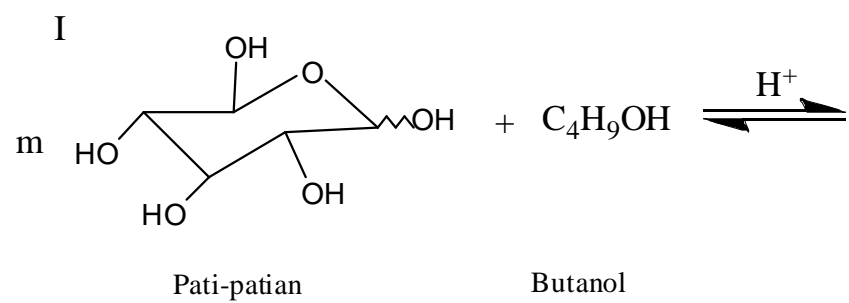

II

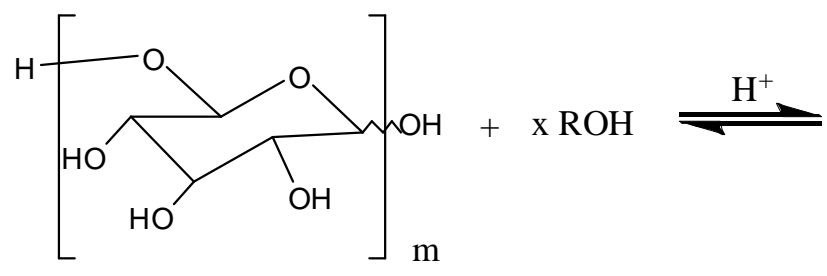

Butil glikosida

Alkohol Lemak
Tahapan selanjutnya yaitu proses transasetalisasi untuk mengganti alkohol rantai pendek dengan alkohol rantai panjang dari alkohol lemak, air dan butanol yang tidak bereaksi dikeluarkan pada tahapan ini. Setelah tahapan transasetalisasi, kemudian dilanjutkan dengan tahap netralisasi. McCurry dkk. (2000), menambahkan $\mathrm{NaBH}_{4}$ setelah proses netralisasi untuk mengubah sisa glukosa yang tidak bereaksi menjadi sorbitol yang memiliki kemampuan lebih tahan pada suhu tinggi selama proses destilasi. Lueders (1991), melakukan penambahan arang aktif $1-10 \%$ sebelum dan sesudah proses destilasi dan diperoleh APG yang lebih jernih pada penambahan sebelum proses destilasi. Reaksi kimia dari proses sintesis APG dapat diliat pada Gambar 1.

Proses pembuatan APG masih didominasi oleh penggunaan pati kentang dan jagung sebagai gugus hidrofilik dan alkohol lemak $\mathrm{C}_{14-18}$ sebagai sumber gugus hidropobik (Hill, 2009). Pada penelitian ini dilakukan proses sintesis APG dengan menggunakan tapioka sebagai sumber pati (hidrofilik) dan alkohol lemak $\mathrm{C}_{12}$ (dodekanol) turunan dari minyak kelapa sawit sebagai gugus hidropobik. Pada penelitian ini juga dilakukan penggabungan metode yang dilakukan oleh McCurry dkk. (2000) dan Lueders (1991) secara bersamaan untuk meningkatkan kecerahan APG yang dihasilkan

Tujuan dari penelitian ini yaitu untuk mengetahui jumlah penambahan $\mathrm{NaBH}_{4}$ dan arang aktif terbaik setelah proses transasetalisasi terhadap karakteristik dan kinerja APG yang dihasilkan.

\section{METODE PENELITIAN}

\section{Alat dan Bahan}

Bahan yang digunakan pada penelitian ini

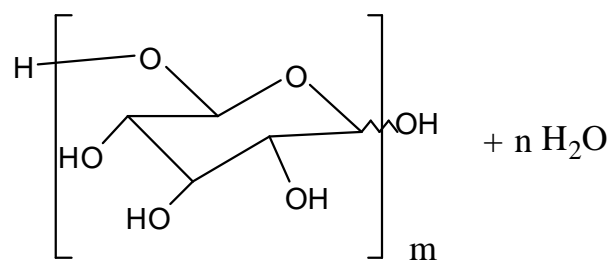

Butil glikosida

Air

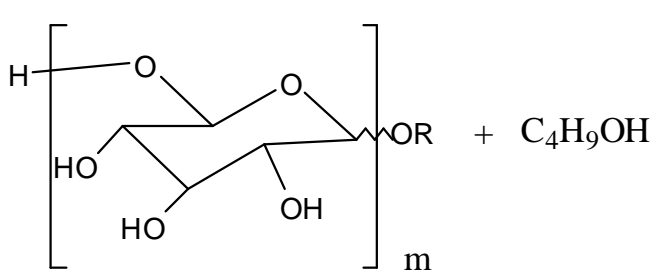

Alkil Poliglikosida

Butanol

I. Tahap glikosidasi (Butanolisis)

II. Tahap Transglikosidasi (Transasetalisasi)

Gambar 1. Proses sintesis APG dua tahap (Hill dkk., 2000) 
adalah tapioka, alkohol lemak $\mathrm{C}_{12}$ (dodekanol) yang diperoleh dari PT. Ecogreen, butanol 95\% teknis diperoleh dari Bratachem, $\mathrm{MgO}$ teknis yang diperoleh dari Bratachem, katalis p-toluena sulfonic acid (PTSA) merk Merck (CAS-No. 657-84-1), akuades, xylene merk Merck (CAS-No. 1330-20-7), pyridina P.A merk Merck (CAS-No. 110-86-1), benzene P.A merk Merck (CAS-No. 71-43-2), 3,5 dinitrosalicylic acid (CAS-No. 609-99-4) Merk Sigma, Phenol (CASNo. 108-92-2) Merk Sigma, D-glukosa standar P.A merk Merck (CAS-No. 50-99-7), $\mathrm{H}_{2} \mathrm{SO}_{4}$ (CAS-No. 7664-93-9) merk Merck, $\mathrm{NaBH}_{4}$ (CAS-No. 16940-662), arang aktif diperoleh dari Bratachem, span20 (CAS-No. 1338-39-2) Merk Sigma, tween80 (CASNo. 9005-65-6), asam oleat (CAS-No. 112-80-1), $\mathrm{NaOH}$ (CAS-No. 12200-64-5) merk Merck, MgO (CAS-No. 1309-48-4), dan $\mathrm{H}_{2} \mathrm{O}_{2} 50 \%$ diperoleh dari Bratachem.

Peralatan yang digunakan pada penelitian ini adalah reaktor double jacket yang dilengkapi dengan termostat, agitator dan motor, kondensor, pompa vakum. Magnetic strirer, oven, tensiometer, vortex mixer, sentrifuse, $\mathrm{pH}$ meter, hot plate, termometer, spectrofotometer, serta peralatan gelas.

\section{Prosedur Penelitian}

Tahap sintesis (proses butanolisis dan transasetalisasi)

Kondisi operasi pada proses butanolisis yaitu menggunakan perbandingan rasio mol katalis ptoluena sulfonic acid : tapioka yaitu 0,027:1. Suhu reaksi pada proses butanolisis yaitu $140^{\circ} \mathrm{C}$, lama reaksi yaitu 30 menit dan menggunakan tekanan 5-7 $\mathrm{kg} / \mathrm{cm}^{2}$ (Bastian, 2011). Hasil dari proses butanolisis akan dilanjutkan pada proses transasetalisasi.

Kondisi operasi pada proses transasetalisasi yaitu dilakukan penambahan alkohol lemak $\mathrm{C}_{12}$ dengan perbandingan rasio mol alkohol lemak : tapioka yaitu 5:1. Suhu reaksi pada tahap transasetalisasi yaitu $115-120^{\circ} \mathrm{C}$ waktu sintesis selama 2 jam dan menggunakan kondisi vakum $(-15 \mathrm{mmHg})$.

Tahap pemurnian (proses netralisasi, destilasi, dan bleaching)

Tahap pemurnian dilakukan setelah proses transasetalisasi. Tahap pemurnian diawali dengan proses penyaringan untuk memisahkan endapan polidekstrosa yang terbentuk, kemudian dilakukan proses netralisasi dengan menggunakan $\mathrm{NaOH} 50 \%$ pada suhu $80^{\circ} \mathrm{C}$ hingga mencapai $\mathrm{pH}$ 9. Proses selanjutnya yaitu penambahan arang aktif $0 \%$ (A1), $5 \%$ (A2) dan $10 \%$ (A3) pada suhu $50^{\circ} \mathrm{C}$ selama 45 menit, kemudian ditambahkan natrium borohidrat $\left(\mathrm{NaBH}_{4}\right)$ dengan konsentrasi $0 \%$ (B1), $0,1 \%$ (B2), $0,2 \%$ (B3) dan $0,3 \%$ (B4). Proses seanjutnya larutan disentrifuse dengan putaran $3000 \mathrm{pm}$ selama 30 menit, kemudian dilakukan destilasi unutk menghilangkan alkohol lemak yang tidak bereaksi pada suhu $140-160^{\circ} \mathrm{C}$ selama 1 jam. Hasil yang diperoleh kemudian dilarutkan dengan menggunakan air hingga diperoleh konsentrasi APG 50\%. Proses selanjutnya yaitu proses pemucatan dengan menggunakan $\mathrm{H}_{2} \mathrm{O}_{2} \quad 35 \%$ sebanyak $2 \%(\mathrm{~b} / \mathrm{b})$ dan ditambahkan magnesium oxide 500 pm pada suhu $70^{\circ} \mathrm{C}$ selama 1 jam.

\section{Karakteristik Produk}

Tiap sampel yang diperoleh kemudian dihitung kecerahan, tegangan permukaan, tegangan antar muka, kestabilan emulsi, tinggi busa, kestabilan busa dan hasil yang terbaik akan dihitung nilai HLB dan dilakukan analisa gugus fungsi FTIR pada perlakuan terbaik.

\section{Pengukuran Kecerahan}

Pengukuran kecerahan dilakukan dengan menggunakan Spectrofotometer pada panjang gelombang 470 (McCurry dkk., 1994).

\section{Pengukuran tegangan permukaan metode Du Nouy (ASTM D-1331.2000)}

Peralatan dan wadah sampel yang digunakan harus dibersihkan terlebih dahulu dengan larutan asam sulfat-kromat dan dibilas dengan aquades, lalu dikeringkan. Cincin platinum yang digunakan pada alat tensiometer dan mempunyai mean circumferense $=5.945$.

Posisi alat diatur agar horizontal dengan water pass dan diletakkan pada tempat yang bebas dari gangguan, seperti getaran, angin, sinar matahari dan panas. Larutan surfaktan dengan ragam konsentrasi, dimasukkan ke dalam gelas kimia dan diletakkan di atas dudukan tensiometer. Suhu cairan di ukur dan dicatat. Selanjutnya cincin platinum dicelupkan ke dalam sampel tersebut (lingkaran logam tercelup \pm 3 $\mathrm{mm}$ di bawah permukaan cincin). Skala vernier tensiometer diatur pada posisi nol dan jarum penunjuk harus berada pada posisi terhimpit dengan garis pada kaca. Selanjutnya kawat torsi diputar perlahan-lahan sampai film cairan tepat putus, saat film cairan tepat putus, skala di baca dan dicatat sebagai nilai tegangan permukaan.

Pengukuran tegangan antar muka (ASTM D-1331. 2000)

Metode menentukan tegangan antarmuka hampir sama dengan pengukuran tegangan permukaan. Tegangan antarmuka menggunakan dua cairan yang berbeda tingkat kepolarannya, yaitu larutan surfaktan dengan ragam konsentrasi dan xylene (1:1). Larutan surfaktan terlebih dahulu dimasukkan ke dalam wadah sampel, kemudian dicelupkan cincin platinum ke dalamnya (lingkaran logam tercelup $\pm 3 \mathrm{~mm}$ di bawah permukaan cincin). Setelah itu, secara hati-hati larutan xylene ditambahkan di atas larutan surfaktan sehingga sistem terdiri atas dua lapisan. Kontak antara cincin dan larutan xylene sebelum pengukuran harus dihindari. Setelah tegangan antarmuka mencapai equilibrium, yaitu benar-benar terbentuk dua lapisan terpisah yang 
sangat jelas, pengukuran selanjutnya dilakukan dengan cara yang sama pada pengukuran tegangan permukaan.

\section{Analisa stabilitas emulsi (Modifikasi ASTM D 1436. 2000)}

Stabilitas emulsi diukur diantara air dan xylene. Xylene dan air dicampur dengan perbandingan $6: 4$. Campuran tersebut dikocok selama 5 menit menggunnakan vortex mixer. Pemisahan emulsi antara air dan xylene diukur berdasarkan lamanya pemisahan antar fasa sebelum dan sesudah ditambahkan surfaktan dibandingkan nilainya. Penetapan stabilitas emulsi dengan cara yang sederhana, yaitu dengan cara pengukuran berdasarkan pemisahan dengan asumsi bahwa sistem emulsi yang sempurna bernilai 100

$$
\% \text { Stabilitas }=\frac{\text { tinggi }(\text { keseluruhan }- \text { pemisahan })}{\text { tinggi keseluruhan }} \times 100
$$

Kestabilan Busa (Sukkary dkk., 2007)

Pengukuran kestabilan busa dilakukan dengan konsentrasi APG 0,5\% yang dilarutkan dalam air. Kemudian dimasukkan $5 \mathrm{ml}$ kedalam tabung ulir 10 ml. Kemudian di kocok hingga busa terbentuk. Busa yang terbentuk kemudian diukur tinggi busa dengan menghitung perbandingan antara tinggi busa dan tinggi keseluruhan larutan + busa. Stabilitas busa dihitung dengan melihat berapa lama busa terbentuk (menit)

\section{Penentuan nilai HLB (Kuang dkk., 2000).}

HLB dari surfaktan APG ditentukan menggunakan metode bilangan air (water number method). Larutan yang mengandung $1 \mathrm{~g}$ surfaktan APG dalam $24 \mathrm{ml}$ campuran piridina dan benzena 95:5 (v/v) dititrasi dengan aquades sampai kekeruhan permanen. Nilai HLB dari dari sampel surfaktan APG diperoleh dengan interpolasi pada kurva standar HLB.

\section{HASIL DAN PEMBAHASAN \\ Analisa Kejernihan}

Hasil penelitian ini menunjukkan nilai \%Transmisi yang dihasilkan berkisar antara 27,8663,68 . Hasil analisa ragam faktor penambahan arang aktif berpengaruh nyata terhadap kejernihan APG yang dihasilkan, demikian pula dari faktor penambahan $\mathrm{NaBH}_{4}$ berpengaruh nyata terhadap kecerahan APG yang dihasilkan. Interaksi kedua faktor antara penambahan arang aktif dan penambahan $\mathrm{NaBH}_{4}$ menunjukkan hasil yang berpengaruh nyata. Hasil uji duncan $(\alpha=0,05)$ menunjukkan faktor penambahan $\mathrm{NaBH}_{4} 0,2 \%$ dan $0,3 \%$ tidak berbeda nyata, namun berbeda nyata dengan penambahan $\mathrm{NaBH}_{4} 0 \%$ dan $0,1 \%$.

Hasil analisa warna menunjukkan penggunaan arang aktif 5\% mampu menghasilkan kejernihan produk yang lebih tinggi dengan nilai \% transmisi yang lebih tinggi. Hal ini disebabkan karena arang aktif mampu menyerap HMF yang terbentuk. Faktor penambahan arang aktif $10 \%$ menyisakan partikel arang aktif yang berlebih yang tersisa pada produk sehingga menyebabkan produk menjadi lebih gelap. Perlakuan penambahan $\mathrm{NaBH}_{4}$ mampu meningkatkan kejernihan produk. Hal ini disebabkan karena $\mathrm{NaBH}_{4}$ mengubah sisa glukosa yang tidak bereaksi menjadi sorbitol yang lebih tahan pada suhu tinggi selama proses destilasi (McCurry dkk., 2000). Glukosa akan terhidrasi pada suhu dan tekanan yang tinggi dan akan menghasilkan senyawa furfural yang menyebabkan produk menjadi gelap (Aida dkk., 2007). Hasil penelitian terhadap warna APG dapat dilihat pada Gambar 2.

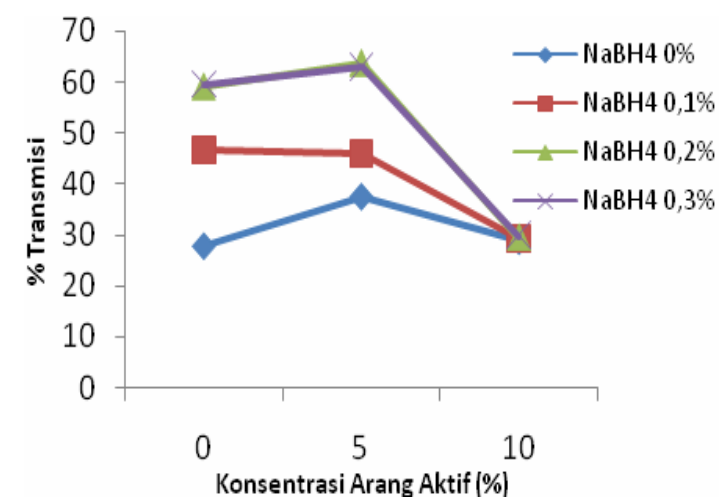

Gambar 2. Hasil analisa kejernihan dengan penambahan arang aktif dan $\mathrm{NaBH}_{4}$

\section{Kemampuan untuk menurunkan tegangan permukaan}

Hasil dari uji kemampuan menurunkan tegangan permukaan air dari APG yang dihasilkan menunjukkan kinerja yang baik. Persentase penurunan tegangan permukaan berkisar antara 60,63-61,94\%. Dari hasil uji ragam, penambahan arang aktif 5\% dan $10 \%$ tidak berbeda nyata dan menunjukkan hasil kemampuan menurunkan tegangan permukaan yang lebih rendah jika dibandingkan dengan tanpa penggunaan arang aktif. Penambahan arang aktif dapat menurunkan kemampuan untuk menurunkan tegangan permukaan. Hal ini disebabkan karena sifat arang aktif yang non polar. Penambahan arang aktif mampu menyerap gugus hidrofobik, surfaktan dapat teradsorpsi pada arang aktif karena interaksi hidrofobik (Rosu dkk., 1997). Penambahan arang aktif 5-10\% dapat menurunkan kinerja APG untuk menurunkan tegangan permukaan, namun jika dilihat dari hasil analisa kejernihan, penambahan hingga 5\% selama proses sintesis dapat meningkatkan kecerahan dari APG yang dihasilkan jika dibandingkan dengan perlakuan tanpa penambahan arang aktif (Gambar 3). Walaupun terjadi penurunan dari kemampuan untuk menurunkan tegangan permukaan, namun nilai kemampuan untuk menurunkan tegangan permukaan dari penambahan arang aktif 5-10\% masih lebih tinggi dibandingkan dengan kemampuan menurunkan tegangan permukaan dari APG komersial. APG 
komersial $\left(\right.$ Glucopon $\left.^{\circledR}\right)$ memiliki kemampuan menurunkan tegangan permukaan sebesar 58,89\%.

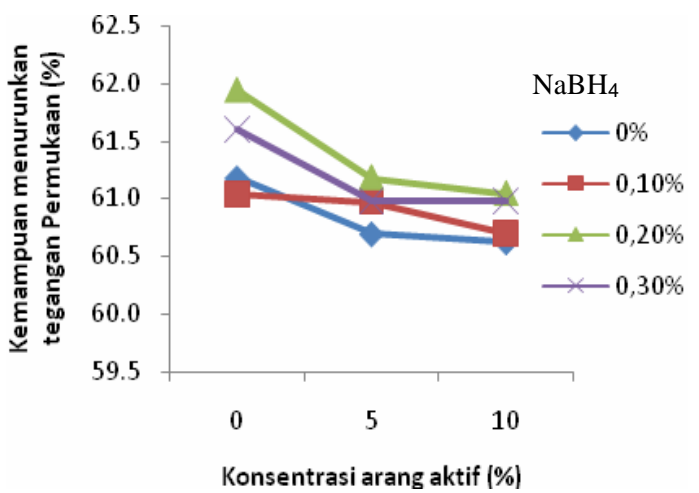

Gambar 3. Kemampuan menurunkan tegangan permukaan dari APG yang dihasilkan

Penambahan $\mathrm{NaBH}_{4} \quad 0,2 \%$ menghasilkan nilai peningkatan kemampuan menurunkan tegangan permukaan yang lebih tinggi. Hasil uji ragam menunjukkan faktor penambahan $\mathrm{NaBH}_{4}$ berpengaruh nyata. Hasil duncan $(\alpha=0,05)$ menunjukkan perlakuan penambahan $\mathrm{NaBH}_{4} 0,1 \%$ tidak berbeda nyata dengan tanpa penambahan $\mathrm{NaBH}_{4}$. Penambahan $\mathrm{NaBH}_{4}$ juga mampu mengurangi pembentukan polydextrose yang dapat menyebabkan penurunan kemampuan menurunkan tegangan permukaan maupun tegangan antar muka. Glukosa yang tidak bereaksi berubah menjadi sorbitol sehingga mengurangi proses terbentuknya polydextrose yang dapat menurunkan kinerja APG. Perhitungan kemampuan menurunkan tegangan permukaan dilakukan pada konsentrasi $1 \%$ APG. Pada konsentrasi yang rendah, molekul surfaktan dalam larutan terabsorpsi pada permukaan udara atau air, jika ditambahkan konsentrasi surfaktan, maka surfaktan akan teradsorpsi pada permukaan hingga mencapai kejenuhan dan tegangan permukaan menjadi konstan, pada tahap ini telah terbentuk misel. Misel terbentuk ketika surfaktan mencapai konsentrasi tertentu yang disebut Critical Micelle Concentration (CMC). Pada konsentrasi dibawah CMC tegangan permukaan dan antar muka akan turun dengan meningkatnya konsentrasi surfaktan. Jika konsentrasinya lebih tinggi maka tidak terjadi penurunan tegangan permukaan atau penurunannya sangat rendah.

\section{Kemampuan menurunkan tegangan antar muka}

Perhitungan penurunan kemampuan tegangan antar muka dilakukan pada laruran air dan xylene. Tegangan antar muka air dan xylene yaitu 42 dyne/cm. Konsentrasi penambahan APG hasil sintesis pada campuran air dan xylene yaitu 0,001-1\%.

APG hasil sintesis dengan konsentrasi $1 \%$ APG memiliki nilai penurunan tegangan antar muka antara 1,85-2,35 dyne/cm atau memiliki nilai kemampuan penurunan tegangan antar muka 95,6-94,4\%. Sedangkan APG komersial (Glucopon ${ }^{\circledR}$ ) memiliki nilai penurunan tegangan antar muka 2,7 dyne/cm
(93,57\%). Hasil uji ragam pada faktor penambahan arang aktif, penambahan $\mathrm{NaBH}_{4}$ berpengaruh nyata, namun interaksi kedua faktor menunjukkan hasil yang tidak berpengaruh nyata. Pada uji duncan $(\alpha=0,05)$ faktor penambahan arang aktif 5\% dan 10\% tidak berbeda nyata namun berbeda nyata terhadap tanpa penambahan arang aktif. Sedangkan penambahan $\mathrm{NaBH}_{4} \quad 0 \%$ dan $0,1 \%$ menunjukkan hasil yang tidak berbeda nyata namun berbeda nyata pada penambahan $\mathrm{NaBH}_{4} \quad 0,2 \%$ dan $0,3 \%$. Hal ini menunjukkan penambahan $\mathrm{NaBH}_{4}$ hingga konsentrasi $0,2 \%$ mampu menaikkan kinerja APG untuk menurunkan tegangan antar muka, namun pada konsentrasi $0,3 \%$ kemampuan untuk menurunkan tegangan antar muka tidak berbeda nyata dengan penambahan $\mathrm{NaBH}_{4}$ $0,2 \%$. Hasil dari perhitungan kemampuan menurunkan tegangan antar muka APG hasil sintesis pada konsentrasi 1\% dapat dilihat pada Gambar 4.

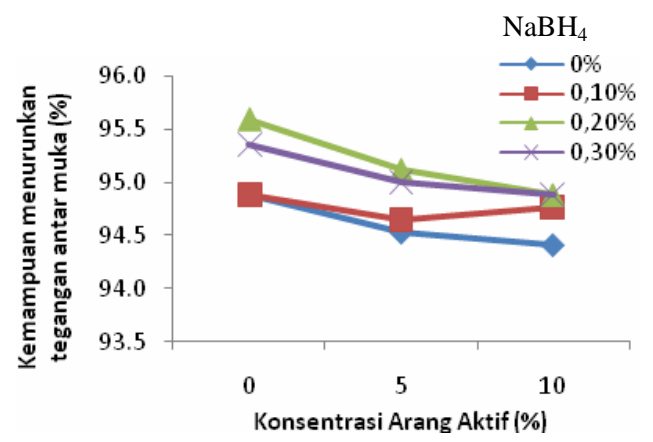

Gambar 4. Kemampuan menurunkan tegangan antar muka APG sintesis pada konsentrasi $1 \%$ bahan aktif

\section{Kestabilan Emulsi}

Emulsi merupakan penyatuan dari dua atau lebih jenis larutan yang tidak saling larut, salah satu cairan terdispersi ke dalam cairan yang lain. Namun karena perbedaan berat molekul ataupun karena pengaruh gaya kohesi maka larutan tersebut secara perlahan akan terpisah lagi. Penghitungan kestabilan emulsi dilakukan dengan menambahkan APG 0,1\% pada laruran air dan xylene kemudian didiamkan selama 300 menit, tinggi emulsi yang terbentuk kemudian diukur untuk melihat kestabilan emulsinya.

Kombinasi penambahan arang aktif $0 \%$ dan $\mathrm{NaBH}_{4}$ 0,2\% menghasilkan tinggi emulsi yang lebih tinggi. Perlakuan kombinasi arang aktif $10 \%$ dan $\mathrm{NaBH}_{4}$ 0\% dan 0,3\% menghasilkan kestabilan emulsi yang paling rendah. Penghitungan kestabilan emulsi dilakukan pada tinggi emulsi pada menit ke 300. Hasil uji ragam menunjukkan pengaruh faktor penambahan arang aktif dan $\mathrm{NaBH}_{4}$ berpengaruh nyata, demikian pula dengan interaksi kedua faktor. Semakin tinggi penambahan arang aktif maka kestabilan emulsi larutan semakin rendah. Sedangkan penambahan $\mathrm{NaBH}_{4} \quad 0,2 \%$ menunjukkan kestabilan emulsi yang lebih tinggi dibandingkan dengan konsentrasi lainnya. Dari hasil uji lanjut Duncan $(\alpha=0,05)$ kombinasi perlakuan arang aktif $0 \%$ dan $\mathrm{NaBH}_{4} \quad 0 \%$; dan kombinasi perlakuan arang aktif $0 \%$ dan $\mathrm{NaBH}_{4} 0,1 \%$ 
menunjukkan tinggi emulsi yang tidak berbeda nyata. Perlakuan kombinasi arang aktif $0 \%$ dan $\mathrm{NaBH}_{4} 0,2 \%$ (A1B3) yang memiliki kestabilan emulsi paling tinggi $(81,71 \%)$ berbeda nyata dengan dengan perlakuan kombinasi arang aktif $5 \% \quad \mathrm{NaBH}_{4} \quad 0,2 \%$ (A2B3), namun perlakuan kombinasi arang aktif $0 \%$ dan $\mathrm{NaBH}_{4} \quad 0,3 \%$ (A1B4) tidak berbeda nyata pada perlakuan A1B3 dan A2B3. Perlakuan kombinasi arang aktif $10 \%$ dan $\mathrm{NaBH}_{4} 0 \%$ dan $0,3 \%$ (A3B1 dan A3B4) merupakan kombinasi perlakuan yang memiliki kestabilan emulsi yang paling rendah yaitu $67,07 \%$, kedua perlakuan ini tidak berbeda nyata dengan perlakuan kombinasi arang aktif $10 \%$ dan $\mathrm{NaBH}_{4}$ 0,1 dan 0,2 (A3B2 dan A3B3) serta perlakuan kombinasi arang aktif 5\% dan $\mathrm{NaBH}_{4} 0 \%$ (A2B1).

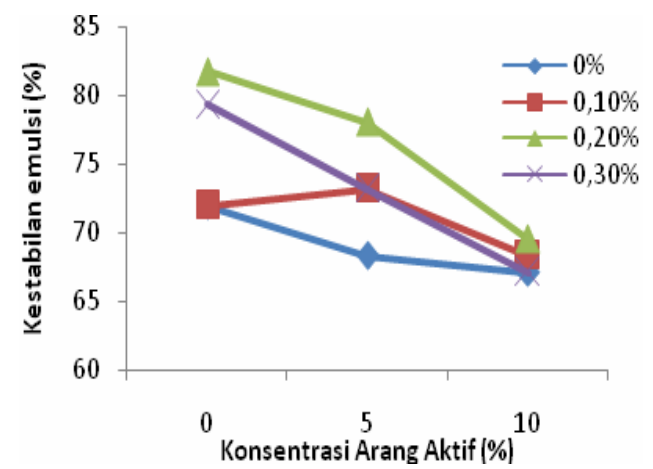

Gambar 5. Tingkat kestabilan emulsi air dan xylene dari penambahan APG

Kestabilan emulsi dipengaruhi oleh gugus hidrofilik dan hidrofobik yang dimiliki oleh APG. Pada pegujian ini digunakan air sebagai bahan polar dan xylene sebagai bahan non polar, penambahan APG diharapkan dapat membentuk emulsi antara air dan xylene. Penambahan arang aktif selama proses sintesis dapat menurunkan jumlah gugus hidrofobik, sehingga kemampuan untuk membuat emulsi antara air dan xylene pun semakin berkurang.

\section{Pembusaan (tinggi busa dan kestabilan busa)}

Kebanyakan surfaktan dalam larutan dapat membentuk busa baik diinginkan maupun tidak diinginkan dalam penggunaannya. Busa cair adalah sistem koloid dengan fase terdispersi gas dan medium pendispersi zat cair. Kestabilan busa diperoleh dari adanya zat pembusa (surfaktan). Zat pembusa ini teadsorpsi ke daerah antar fase dan mengikat gelembung-gelembung gas sehingga diperoleh suatu kestabilan (Suryani, 2008).

Hasil sidik ragam menunjukkan perlakuan penambahan arang aktif tidak berpengaruh nyata antara tanpa penambahan arang aktif, penambahan arang aktif $5 \%$ dan $10 \%$. Namun faktor perlakuan penambahan $\mathrm{NaBH}_{4}$ berpengaruh nyata terhadap tinggi busa yang dihasilkan. Interaksi kedua faktor tidak berpengaruh nyata terhadap tinggi busa yang dihasilkan. Tinggi busa yang dihasilkan berkisar antara 55-62\%, sedangkan tinggi busa dari APG komersial yaitu $67,5 \mathrm{~mm}$. Tinggi busa yang dihasilkan dari penelitian ini dapat dilihat dari Gambar 6 .

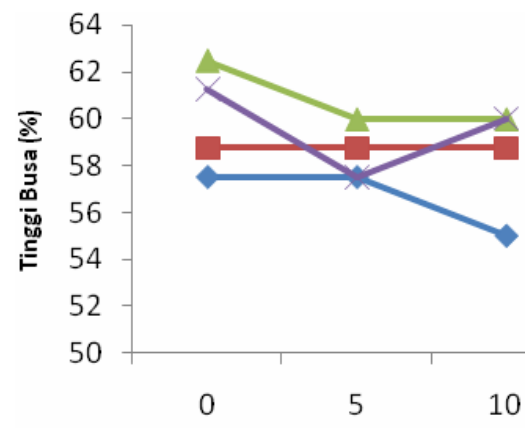

Konsentrasi Arang Aktif

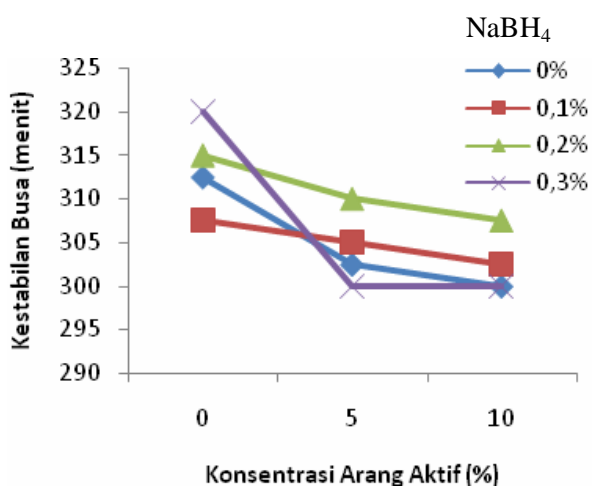

Gambar 6. Perbandingan tinggi busa dan umur busa tiap perlakuan dengan penambahan APG $0,1 \%$

Stabilitas busa adalah lama terbentuknya busa Hasil penelitian menunjukkan bahwa kestabilan busa berkisar antara 300-315 menit. Analisa sidik ragam menunjukkan faktor penambahan arang aktif, penambahan $\mathrm{NaBH}_{4}$, dan interaksi kedua faktor berpengaruh nyata. Hasil uji duncan $(\alpha=0,05)$ menunjukkan penambahan arang aktif 5\% tidak berbeda nyata dengan tanpa penambahan arang aktif, namun berbeda nyata dengan penambahan $10 \%$. Sedangkan penambahan $\mathrm{NaBH}_{4} 0 \%, 0,1 \%$ dan $0,3 \%$ tidak berbeda nyata namun berbeda nyata terhadap penambahan $\mathrm{NaBH}_{4} \quad 0,2 \%$. Umur busa yang dihasilkan dari penelitian ini dapat dilihat pada Gambar 6. Penambahan $\mathrm{NaBH}_{4}$ menyebabkan perubahan glukosa menjadi sorbitol, dengan mengubah struktur aldehid glukosa menjadi stuktur gugus alkohol. Dengan perubahan ini dapat menyebabkan berkurangnya pembentukan polydekstrose yg dapat menurunkan kinerja APG.

\section{Karakteristik formasi emulsi dengan menentukan nilai HLB}

Hydrophilic Lipophilic Balance (HLB) merupakan nilai perbandingan gugus hidrofilik dan lipofilik pada surfaktan. Semakin panjang rantai lipofilik, maka semakin rendah nilai HLB. Surfaktan dengan nilai HLB yang rendah larut dalam minyak 
dan meningkatkan emulsi air dalam minyak (w/o). Sebaliknya surfaktan dengan nilai HLB tinggi akan larut dalam air dan meningkatkan emulsi minyak dalam air $(\mathrm{o} / \mathrm{w})$. Nilai HLB berkisar antara 1-20 (Holmberg dkk., 2003).

Fungsi surfaktan ditentukan dari nilai HLB surfaktan yang akan digunakan. Metode untuk menentukan HLB dari APG yang digunakan adalah metode titrimetri dengan metode bilangan air (water number method). Kepala polar yang diperoleh dari glukosa yang bersifat hidrofilik akan tarik menarik dengan molekul air yang besifat polar dan ion nitrogen dari piridina yang bersifat non polar. Ekor dari APG yang diperoleh dari alkohol lemak bersifat hidrofobik akan menarik molekul benzena yang non polar dan cincin heterosiklik aromatik molekul piridina. Titik akhir titrasi dicapai pada saat kekeruhan permanen. Pada kondisi tersebut larutan telah jenuh dan molekul APG sudah tidak dapat berikatan dengan molekul air maupun piridina dan benzena.

Perhitungan nilai HLB dengan mencari persamaan liniar dari jenis surfaktan yang telah diketahui nilainya. Nilai HLB tween80 ialah 15 , nilai HLB span20 adalah 8,6 dan asam oleat adalah 1. Dari data tersebut dibuatkan kurva standarnya, dimana pada perhitungan HLB selanjutnya menggunakan kurva standar tersebut untuk menentukan nilai HLB. Kurva standar HLB yang diperoleh memiliki Persamaan linear $\mathrm{y}=0,259 \mathrm{x}-2,38$ yang kemudian digunakan untuk menentukan nilai HLB dari APG sintesis dan APG komersial. Nilai HLB APG perlakuan terbaik yang diperoleh yaitu 10,24, sedangkan APG Komersial yaitu 12,01. Dengan demikian APG hasil sintesis merupakan APG golongan pengemulsi o/w. demikian pula APG komersial yang juga masuk dalam nilai kisaran jenis surfaktan pengemulsi o/w.

\section{Analisa Gugus Fungsi}

Spektrofotometer infra merah transformasi fourier (FTIR) merupakan alat untuk mendeteksi gugus fungsi suatu senyawa dengan spektrum infra merah dari senyawa organik yang memiliki sifat fisik yang khas. Energi radiasi inframerah akan diabsorpsi oleh senyawa organik sehingga molekulnya akan mengalami rotasi atau vibrasi. Setiap ikatan kimia yang berbeda seperti $\mathrm{C}-\mathrm{C}, \mathrm{C}-\mathrm{H}, \mathrm{C}=\mathrm{O}, \mathrm{O}-\mathrm{H}$ dan sebagainya mempunyai frekuensi vibrasi yang berbeda.

Hasil analisa FTIR (Gambar 7) menunjukkan peak yang hampir sama antara APG sintesis dan APG komersial. Gugus eter (C-O-C) pada APG hasil sintesis terdapat pada serapan jumlah gelombang $1.151,72 \mathrm{~cm}-1$ sedangkan APG komersial terdapat pada serapan jumlah gelombang 1.153,02 cm-1. Gugus $\mathrm{OH}$ pada APG hasil sintesis terdapat pada serapan jumlah gelombang 3.368,60 cm-1 sedangkan APG komersial terdapat pada serapan jumlah gelombang $3395,15 \mathrm{~cm}-1$. Hal ini sesuai pendapat
Sukkary dkk. (2007), bahwa gugus eter (C-O-C) sebagai komponen gugus utama pada APG terdapat pada serapan jumlah gelombang 1120-1170 $\mathrm{cm}^{-1}$, sedangkan gugus $\mathrm{OH}$ terbentuk pada serapan jumlah gelombang 3200-3400 $\mathrm{cm}^{-1}$. Terbentuknya gugus eter menandakan bahwa sintesis antara glikosida dan alkohol lemak telah terbentuk dan struktur gugus hidrofobik telah terbentuk, sedangkan gugus $\mathrm{OH}$ menandakan gugus hidrofilik dari APG.

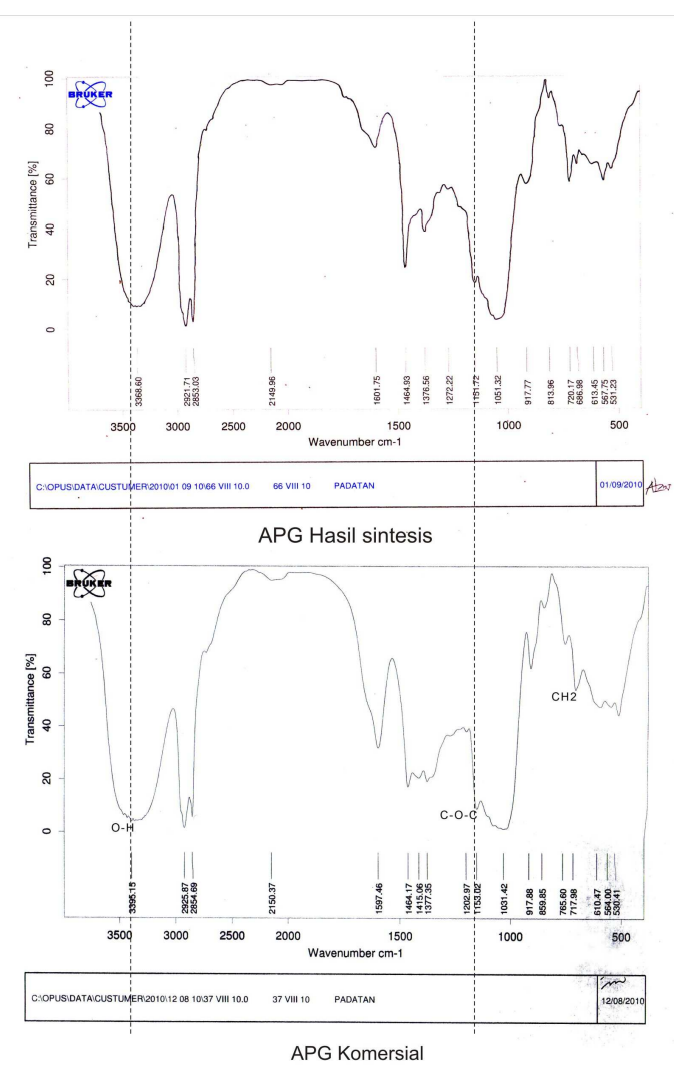

Gambar 7. Perbandingan gugus fungsi FTIR antara APG hasil sintesis dan APG komersial

\section{KESIMPULAN}

Penambahan arang aktif hingga 5\% mampu meningkatkan kecerahan pada produk APG yang dihasilkan, namun penambahan arang aktif mampu menurunkan kemampuan untuk menurunkan tegangan permukaan, tegangan antar muka, dan kestabilan emulsi. Penambahan $\mathrm{NaBH}_{4}$ hingga 2\% mampu meningkatkan kecerahan dan memiliki nilai kemampuan menurunkan tegangan permukaan, tegangan antar muka, dan kestabilan emulsi yang tinggi.

Secara keseluruhan perlakuan terbaik pada proses sintesis adalah kombinasi penambahan konsentrasi arang aktif 5\% dan $\mathrm{NaBH}_{4}$ 0,2\% dilihat dari karakteristik warna $(63,68 \% \mathrm{~T})$ dan kinerja produk yaitu kemampuan untuk menurunkan tegangan permukaan $(61,18 \%)$, kemampuan untuk menurunkan tegangan antarmuka $(95,12 \%)$, stabilitas emulsi $(78,05 \%)$, tinggi busa $(60 \%)$ dan kestabilan busa (315 
menit). Hasil analisa gugus fungsi APG sintesis menunjukkan lintasan yang mirip dengan APG komersial. Nilai HLB APG hasil sintesis dan APG komersial masuk dalam kisaran surfaktan pengemulsi $\mathrm{o} / \mathrm{w}$.

Kemampuan untuk menurunkan tegangan permukaan dan tegangan antar muka serta kestabilan emulsi APG hasil sintesis memiliki nilai yang lebih tinggi dibandingkan dengan APG komersial, namun nilai kejernihan dan pembusaan APG hasil sintesis lebih rendah jika dibandingkan dengan APG komersial.

\section{DAFTAR PUSTAKA}

Aida, T.M., Sato, Y., Watanabe, M., Tajima, K., Nonaka, T., Hattori, H., and Arai, K., (2007), Dehydration of D-glucose in high temperature water at pressures up $80 \mathrm{MPa}$, J. of Supercritical Fluid, 40, pp. 381-388.

Bastian, F., (2011), Pemurnian Surfaktan Nonionik Alkil Poliglikosida Berbasis Tapioka dan Dodekanol, Master Thesis, Institut Pertanian Bogor, Indonesia.

Eskuchen, R. and Nitsche, M., (1997), Technology and Production of Alkyl Poliglycosides, di dalam: Hill, K., von Rybinski, W., and Stoll, G., Editor, 1997, Alkyl Polyglicoside: Technology, Properties and Applications, New York : VCH Publishers, pp. 10-11.

Hill, K., (2009), Alkyl Polyglycosides-Where Green Meets Performance, SOFT Journal, 2, pp. 6-14.

Hill, K., von Rybinski, W., and Stoll, G., (2000), Alkyl Polyglicoside: Technology, Properties and Applications, New York, VCH Publishers.
Holmberg, K., Jönsson, B., Kronberg, B., and Lindman, B., (2003), Surfactants and Polymers in Aqueous Solution, edisi ke-2, Wiley, New York.

Lueders, H., (1991). Method of Manufacturing Alkyloligoglycosides, US Patent No. 4990605.

McCurry, Pattrick Jr., Klein, Robert L., Gibson, Michael, W., Beaulieu, James, D., and Varvil, J.R., (1994), Continuous Bleaching of Alkylpolyglycosides, US. Patent No. 5362861.

McCurry, Pattrick Jr., and Pickens, C.E., (2000), Process for Preparation of Alkylglycosides, US. Patent No. 4950743.

Mehling, A., Kleber, M., and Hensen, H., (2007), Comparative Studies on the Ocular and Dermal Irritation Potential of Surfactants, Journal Food and Chem Toxicol, 14, pp. 747-758.

Rosu, M., Anita M., Aydin K., dan Adrian S., (2007), Surfactant adsorption onto activated carbon and its effect on absorption with chemical reaction, J. Chem. Eng. Sci., 62, pp. 7336-7343.

Sukkary, M.M., Nagla, A., Aid, S.I., and Azab, W.I., (2007), Synthesis and Characterization of Some Alkyl Polyglycosides Surfactans, Journal of Dispersion and Technology, 2, pp. 129-137.

Suryani, A., Dadang, Setyadjit, Tjokrowardoyo, A. S., dan Noerdin, M., (2008), Sintesis Alkil Poliglikosida (APG) Berbasis Alkohol Lemak dan Pati Sagu Untuk Formulasi Herbisida, J. Pascapanen, 5 (1), hal. 10-20.

Wuest, W., Eskuchen, R., Wollman, J., Hill, K., Biermann, M., (1992), Process for Preparing Alkylglucoside Compounds from Oligo- and/or Polysaccharides, US Patent No.005138046. 